\title{
Logical Condition
}

National Cancer Institute

\section{Source}

National Cancer Institute. Logical Condition. NCI Thesaurus. Code C47953.

An assumption on which rests the validity or effect of something else. 